\title{
Insulin Detemir
}

National Cancer Institute

\section{Source}

National Cancer Institute. Insulin Detemir. NCI Thesaurus. Code C65920.

A long-lasting, recombinant version of human insulin. It is an insulin analogue with myristic acid bound to the lysine at position B29 and a deletion of B30. 